\title{
Endospanin Is a Candidate for Regulating Leptin Sensitivity
}

\author{
Richard L. Londraville ${ }^{1 *}$, Matthew Tuttle ${ }^{1}$, Qin Liu ${ }^{1}$ and Janna M. Andronowski \\ ${ }^{1}$ Program in Integrated Bioscience, Department of Biology, University of Akron, Akron, OH, United States, ${ }^{2}$ Division \\ of BioMedical Sciences, Faculty of Medicine, Memorial University of Newfoundland, St. Johns, NL, Canada
}

The hypothesis advanced is that endospanin, a highly conserved vesicle traffic protein in vertebrates, regulates leptin sensitivity in bone signaling. The effects of leptin on bones are well-studied but without consensus on whether the increases in leptin signaling stimulate bone gain or loss. The bone response may depend on leptin sensitivity, and endospanin is an established modulator of leptin sensitivity. An argument is advanced to develop zebrafish models for specific leptin signaling pathways. Zebrafish have well-developed molecular tools (e.g., CRISPR) and the advantage of non-destructive sampling of bones in the form of scales. Using these tools, experiments are described to substantiate the role of endospanin in zebrafish bone dynamics.

Keywords: fish, bone, LEPROT, OBRGRP, leptin receptor (LEPR), leptin resistance

\section{OPEN ACCESS}

Edited by:

Harbindarjeet Singh, Universiti Teknologi MARA, Malaysia

Reviewed by:

Katherine J. Motyl, Maine Medical Center, Maine Health United States

Beth Bragdon, Boston University, United States

*Correspondence: Richard L. Londraville londraville@uakron.edu

Specialty section: This article was submitted to Metabolic Physiology, a section of the journal Frontiers in Physiology

Received: 30 September 2021 Accepted: 25 November 2021 Published: 07 January 2022

Citation: Londraville RL, Tuttle M, Liu Q and Andronowski JM (2022) Endospanin Is a Candidate for Regulating Leptin Sensitivity. Front. Physiol. 12:786299. doi: 10.3389/fphys.2021.786299

\section{INTRODUCTION}

After the Friedman Lab's original paper established leptin's effects on appetite and metabolic rate (Zhang et al., 1994), thousands of studies expanded leptin's pleiotropic effects to include sexual maturity, angiogenesis, immune/stress responses, and bone dynamics (reviewed in Copeland et al., 2011; Londraville et al., 2014, 2017; Guzmán et al., 2019; Münzberg et al., 2020). Leptin’s effects on bone metabolism in mammals is a central focus of intense research effort, leading to two conflicting models. One model predicts that leptin reduces bone mass through a hypothalamic relay and that peripheral leptin signaling does not play a significant role (Ducy et al., 2000). In contrast, another model asserts that leptin builds bone mass through signaling from both peripheral and central leptin pools (Turner et al., 2013). Although most studies use rodent models for studies that investigate leptin's effects on bone, the disparate reported effects also extend to reports on humans (Table 1). Large-scale studies in humans demonstrate a positive correlation between leptin titer and bone mineral density (Ruhl and Everhart, 2002), although that correlation decreases in magnitude or turns negative after correcting for the body mass index (BMI) (Ruhl and Everhart, 2002; Meng et al., 2019). Whether augmented leptin signaling increases or decreases bone mass (or some correlate of bone mass, e.g., bone mineral density-a densitometric scan compared to a standard, or bone volume-density per measured volume of bone) remains unresolved.

Numerous studies provide important details that underscore the complexity of leptin's action on bones. Initially, the discrepancy among models was attributed to administering leptin centrally ( via the central nervous system, behind the blood-brain barrier) vs. peripherally (via vasculature). Central leptin delivery was reported to reduce bone mass (Ducy et al., 2000), whereas peripheral leptin administration increased bone density (Burguera et al., 2001), advancing the hypothesis that the total skeletal bone density was a balance of these positive and negative effects (Burguera et al., 2001). Turner et al. (2013) challenged this with a single study using various approaches to rescue leptin signaling in $o b / o b$ mice (mutant mice that do not express circulating leptin); the results of 
those multiple approaches supported a bone-building role for leptin, primarily from peripheral leptin. Briefly, the $o b / o b$ mice were given subcutaneous leptin injections (peripheral), or leptin gene therapy delivered into the third ventricle of the brain (central). Leptin injections increased the bone formation rate in $o b / o b$ mice to that of (or above) wild-type, and the leptin gene therapy in the hypothalamus returned mineralized bone area in $o b / o b$ mice to that of wild-type (Turner et al., 2013). Peripheral leptin's effects are qualitatively different than leptin delivered through the central nervous system; central gene therapy that causes rats to lose weight does not change their cancellous bone volume when compared with control vectors (Turner et al., 2015) and the bone-specific elimination of leptin signaling does not affect the whole-animal metabolic rate in mice (Yue et al., 2016). In addition, bones respond to peripheral changes in leptin titer at lower doses than those that affect energy metabolism (Philbrick et al., 2017). Finally, it does not appear that leptin's effects on bones are secondary to other effects. For example, ob/ob mice are sexually immature, and leptin can rescue wild-type sexual maturation (Chehab et al., 1996). Since estrogen signaling also affects the bone and contributes to bone remodeling (Beekman et al., 2019), leptin's effects on bone may interact with leptin's effects on estrogen signaling. Mice without ovaries still respond to increases in leptin signaling (Ducy et al., 2000; Burguera et al., 2001; Table 1). Further, Turner et al. (2017) used an estrogen receptor antagonist in $o b / o b$ mice and demonstrated that leptin still rescues bone length and volume in the absence of estrogen signaling.

Adding to the complexity of the bone's response to leptin is the fact that leptin signaling changes do not have equivalent effects on all parts of the skeleton, which may contribute to the diversity of effects reported (Table 1). Rodent models remove leptin signaling through mutations that eliminate leptin expression $(o b / o b)$ or leptin-receptor expression ( $d b / d b$ mice and $f a / f a$ rats). These mutant models generally have increased cancellous bone volume in the lumbar vertebrae and decreased bone mineral content and length in long bones. Generally, these changes reverse with leptin administration (summarized in Reid et al., 2018).

Clearly, the effects of leptin on bone in mammals are complex but real. Individual studies are carefully executed, with well-reasoned (but contradictory) conclusions. Hamrick (2004) proposed a synthesis of these results, hypothesizing that leptin promotes satiety, sexual maturity, and growth (bone deposition) in concert during adolescence, and inhibits these

TABLE 1 | Effects of changes in leptin signaling on bones.

\begin{tabular}{|c|c|c|c|c|c|c|}
\hline $\begin{array}{l}\text { Study } \\
\text { organism }\end{array}$ & $\begin{array}{l}\text { Genotype/ } \\
\text { phenotype }\end{array}$ & Bone(s) & Treatment and result & $\begin{array}{l}\text { Leptin } \\
\text { signaling }\end{array}$ & $\begin{array}{l}\text { Effect on } \\
\text { bone }\end{array}$ & References \\
\hline Rat & $\mathrm{fa} / \mathrm{fa}$ & Femur & $\mathrm{fa} /$ fa rats compared to wt & $\downarrow$ & $\downarrow$ & Foldes et al., 1992 \\
\hline Mouse & $d b / d b$ & Femur & $\begin{array}{l}d b / d b \text { vs. wt after } 8 \text { weeks } \\
\text { development }\end{array}$ & $\downarrow$ & $\downarrow$ & Takeshita et al., 1995 \\
\hline Mouse & OVX ob/ob & Tibia and vertebrae & ICV infusion of leptin in OVX ob/ob & $\uparrow$ & $\downarrow$ & Ducy et al., 2000 \\
\hline Rat & OVX wt & Tibia & Peripheral leptin implant in OVX wt & $\uparrow$ & $\uparrow$ & Burguera et al., 2001 \\
\hline Mouse & $\begin{array}{l}\text { STZ-induced } \\
\text { diabetic wt }\end{array}$ & Tibia & $\begin{array}{l}\text { Peripheral leptin implant in } \\
\text { STZ-diabetic wt }\end{array}$ & $\uparrow$ & $\leftarrow$ & $\begin{array}{l}\text { Motyl and McCabe, } \\
2009\end{array}$ \\
\hline Rat & wt & Tibia & $\begin{array}{l}\text { Hind limb unloading with peripheral } \\
\text { leptin implant }\end{array}$ & $\uparrow$ & $\uparrow$ & $\begin{array}{l}\text { Baek and Bloomfield, } \\
2009\end{array}$ \\
\hline Mouse & $a b / o b$ & Femur + vertebrae & Subcutaneous leptin injection & $\uparrow$ & $\uparrow$ & Turner et al., 2013 \\
\hline Rat & wt & Femur + vertebrae & $\begin{array}{l}\text { Gene therapy to increase leptin } \\
\text { expression in CNS }\end{array}$ & $\uparrow$ & $\leftarrow \rightarrow$ & Turner et al., 2015 \\
\hline Human & & Hip & $\begin{array}{l}\text { Correlation between serum leptin } \\
\text { and bone mineral density }\end{array}$ & $\uparrow$ & $\begin{array}{l}\downarrow \sigma^{\pi} \\
\leftarrow \rightarrow \text { む }\end{array}$ & $\begin{array}{l}\text { Ruhl and Everhart, } \\
2002\end{array}$ \\
\hline Human & $\begin{array}{l}\text { Hypothalamic } \\
\text { amenorrhea }\end{array}$ & Total skeleton & Subcutaneous leptin injection & $\uparrow$ & $\begin{array}{c}\leftarrow \rightarrow \text { (bone } \\
\text { density) } \\
\uparrow \text { (alkaline } \\
\text { phosphatase) }\end{array}$ & Welt et al., 2004 \\
\hline Human & Gastric bypass & Radius Hip Lumbar spine & Pre vs. post gastric bypass & $\downarrow$ & $\downarrow$ & Johnson et al., 2005 \\
\hline Human & $\begin{array}{l}\text { Hypothalamic } \\
\text { amenorrhea }\end{array}$ & Spine, upper and lower limbs & Intense exercise (ballet dancer) & $\downarrow$ & $\downarrow$ & Kaufman et al., 2002 \\
\hline Zebrafish & $\begin{array}{l}\text { Morpholino } \\
\text { knockdown of } \\
\text { leptin }\end{array}$ & Otolith & knockdown vs. control & $\downarrow$ & $\downarrow$ & Liu et al., 2012 \\
\hline Zebrafish & High-fat diet & Scale & High-fat diet vs. control & $\uparrow$ & $\downarrow$ & Carnovali et al., 2018 \\
\hline
\end{tabular}

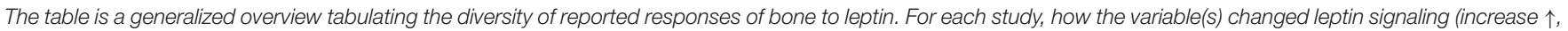

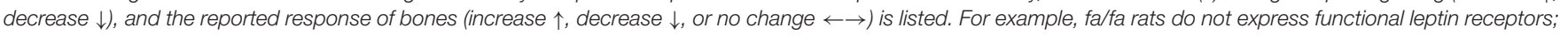

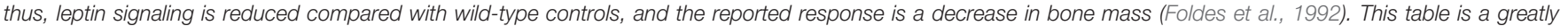

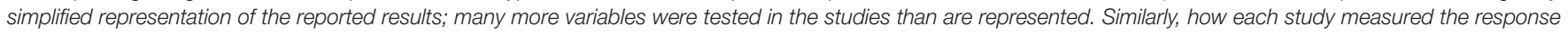
of bone is diverse (including bone volume, bone mineral density, bone area, enzyme activity, etc.) and is not intended to be equivalent across studies.

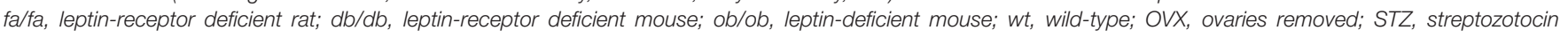
antibiotic (used to induce diabetes). 
physiological axes during food limitation. Further, he proposed that changes in leptin sensitivity contribute to the diversity of the bone responses reported (Hamrick, 2007). We extend that idea and propose a mechanism for leptin sensitivity change. We advance the hypothesis that multiple bone cell types and their progenitors differ in their leptin sensitivity depending on leptin receptor expression, which changes across different physiological states and biomechanical stimuli. For example, $o b / o b$ mice are extremely leptin sensitive due to high leptin receptor cell-surface localization (Tortoriello et al., 2007), and therefore, bone density responds to increased leptin signaling. Similarly, different bones are composed of different cell populations. These populations likely vary in leptin receptor expression and physiological stimuli; thus, leptin response is not uniform across all bone tissues. Below we develop the hypothesis that leptin receptor expression, and thus, leptin sensitivity, is modulated through endospanin.

\section{Endospanin Is a Regulator of Leptin Receptor Cell-Surface Expression}

Endospanin was first described as the product of an alternate start-site under control of the same promoter as the leptin receptor (Bailleul et al., 1997). Originally named the leptin receptor overlapping transcript (LEPROT), or obese receptor gene-related product $(O B R G R P)$, it was renamed endospanin by Séron et al. (2011) for its late endosomal/Golgi localization and membrane-spanning topology. Two paralogs of endospanins are expressed in mammals, with endospanin-1 facilitating endocytosis and lysosome targeting of leptin receptor; thus endospanin-1 expression is negatively correlated with cell surface (active) leptin receptors and negatively correlated with leptin sensitivity (Roujeau et al., 2019). The LEPROT gene copy number and leptin receptor ( $L E P R)$ expression are also negatively correlated in humans (Jeon et al., 2010). Further, endospanin1 knockdown mice (targeting hypothalamus) are highly leptin sensitive and resistant to diet-induced obesity (Couturier et al., 2007). Endospanin-2 affects the skeletal muscle aerobic capacity (Lancel et al., 2018), and therefore also may be correlated with leptin sensitivity.

The endospanin-1 gene (LEPROT) is extremely conserved throughout the metazoa, including recognizable endospanin homologs in invertebrates, fungi, and plants (Londraville et al., 2017). Its in silico predicted structure contains several conserved amino acids, 4 transmembrane domains, and a highly conserved hydrophobic core (Londraville et al., 2017). Endospanins (as a family) may have a generalized vesicle traffic function. Indeed, endospanins are associated with RAS associated binding (RAB) proteins (small RAS GTPases) that facilitate vesicle traffic (Hirvonen et al., 2013). However, there is also evidence that endospanins specifically evolved to regulate leptin receptor expression. All classes of vertebrates (except one) have an endospanin gene with loci either within the LEPR gene (via an alternate start site as in humans) or within 150,000 bp of the leptin receptor gene and with no intervening gene (Londraville et al., 2017). Since genes in close proximity have similar transcription rates (Akhtar et al., 2013), it is a reasonable hypothesis that the transcription of endospanin and leptin receptors is co-regulated. The one exception to this $L E P R O T / L E P R$ gene synteny is in Teleost fish, where endospanin (LEPROT) and LEPR are on separate chromosomes (Londraville et al., 2017).

Our laboratory is testing the hypothesis that the interaction of endospanin and leptin receptor expression is fundamentally different in a Teleost (zebrafish). Adding zebrafish to the rodent models in the effort to understand the dynamics of leptin/bone signaling serves (at least) four purposes. First, repeating (in zebrafish) the approaches taken in rodents will add weight to either the "increase" or "decrease" camp (Table 1), assuming that the response to leptin is evolutionary conserved from fish to rodents. This is similar to the approach used to test the conservation of other leptin functions, such as its lipostatic or anorectic effects (Copeland et al., 2011; Londraville et al., 2014, 2017). Second, zebrafish have the advantage of non-destructive sampling of bones (scales), allowing for longitudinal studies within individuals. Third, zebrafish can regenerate bones (caudal amputation, reviewed in Tonelli et al., 2020). Finally, we can test whether gene architecture affects leptin signaling (e.g., proximity of endospanin and leptin receptor in the genome) as these differ between rodents and zebrafish. The fact that endospanin and leptin receptors have loci on different chromosomes in zebrafish allows selective knockout of each gene without the confounding concern that knockout of one will affect transcription of the other (as in mammals due to gene proximity).

\section{DISCUSSION}

\section{Testable Hypotheses on Endospanin Function in Zebrafish}

Our overarching hypothesis is that endospanin modulates how bone responds to leptin signaling in zebrafish. Zebrafish have similar bone development to mammals, including the expression of lepr in hypertrophic chondrocytes, analogous to mice (Giovannone et al., 2019). Zebrafish also have mineralized scales, which can be non-destructively sampled, treated in cell culture, and serve as a proxy for the response of a skeletal bone (Carnovali et al., 2018). Zebrafish are already established as model organisms for several human skeletal diseases (Seth et al., 2013), including osteoporosis and osteoarthritis (Lleras-Forero et al., 2020). Zebrafish bones also respond to changes in leptin signaling (Liu et al., 2012; Carnovali et al., 2018; Giovannone et al., 2019). Recently, leptin-signaling knockout lines have been developed in zebrafish, similar to the ob/ob mouse (Michel et al., 2016; He et al., 2021; Kamstra et al., 2021).

In Teleost fish, as in mammals, some data support a positive correlation between leptin signaling and bone volume (Yang et al., 2008; Liu et al., 2012), and a negative correlation between leptin signaling and bone volume (Carnovali et al., 2018; Giovannone et al., 2019; Table 1). We suggest that this apparent conundrum can be resolved by understanding the endospanin function. In developing fish, robust leptin signaling [Lep binding to LepR, stimulating Jak/Stat signaling, increasing phosphorylation of signal transducer and activator of transcription (STAT), Figure 1] is hypothesized to result in osteoblast stimulation and increased bone volume (Yang et al., 2008; Liu et al., 2012). In adult fish, a high-fat diet (HFD) increases the expression of leptin 
Developing Zebrafish (<3 months)
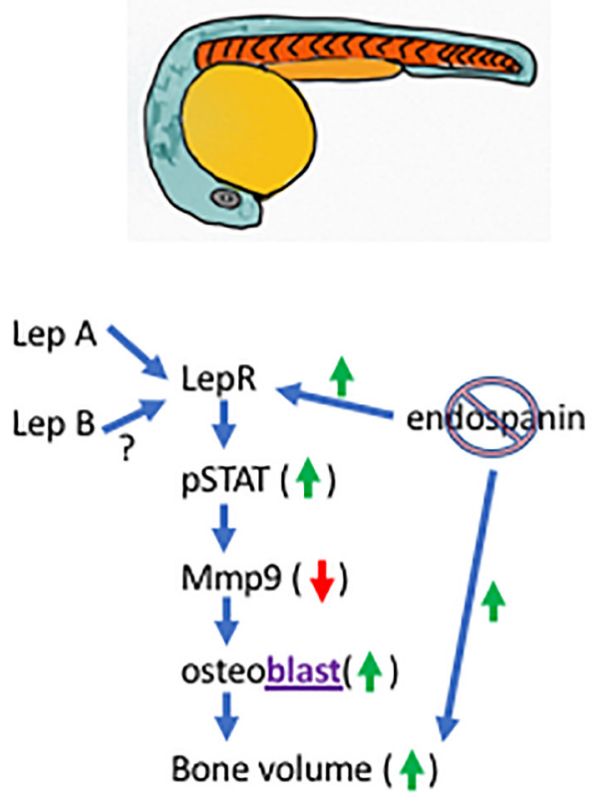

Zebrafish adults and scale explants (>3 months)
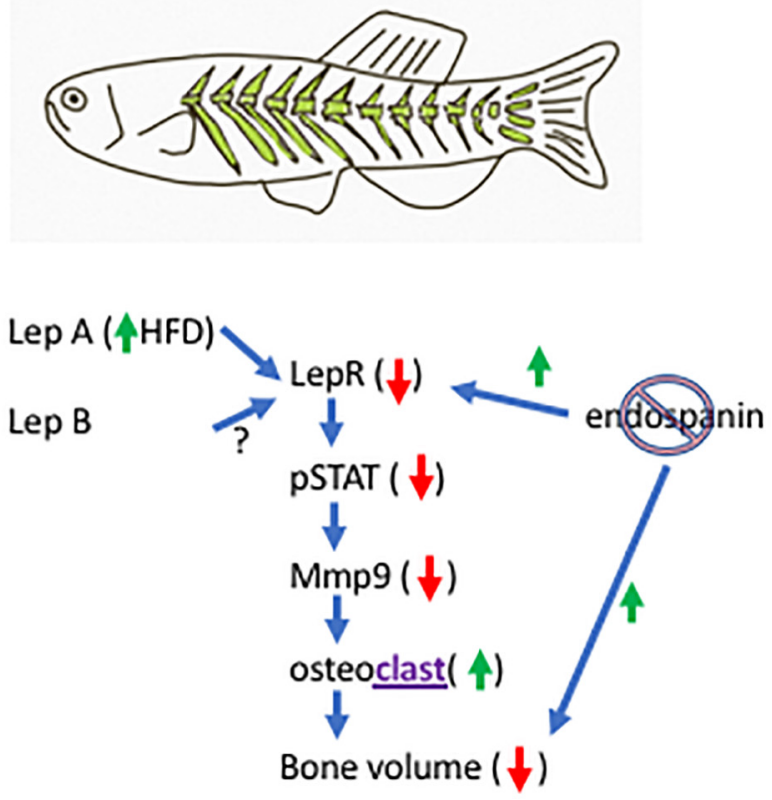

FIGURE 1 | Model of the endospanin modulation of leptin sensitivity in zebrafish. In developing zebrafish (left), endospanin knockout is predicted to increase bone volume through increased cell-surface leptin receptor expression (LepR), increase leptin signaling [through increased phosphorylation of signal transducer and activator of transcription (STAT)], decrease expression of matrix metalloproteinase 9 (Mmp9) and increase the activity of osteoblasts. In adult zebrafish (right), high fat diet is predicted to decrease bone volume through lower leptin sensitivity (decreased cell-surface leptin receptor expression), lower expression of Mmp9, and increased osteoclast activity. Endospanin knockout in adults is predicted to restore leptin sensitivity (increased LepR surface expression) and bone volume.

(Carnovali et al., 2018). We hypothesize that this decreases the expression of LepR on the cell surface (leptin resistance), subsequently decreasing the Jak/Stat signaling and decreasing the phosphorylation of STAT, which lowers the activity of matrix metalloproteinase 9 [required for bone remodeling (Giovannone et al., 2019)], increases the activity of osteoclasts (Carnovali et al., 2018), and decreases bone volume. Bone response to leptin signaling, therefore, is hypothesized to depend on developmental contexts and leptin sensitivity.

We hypothesize that leptin sensitivity is modulated by endospanin. If endospanin functions in zebrafish as it does in mice, eliminating its expression (CRISPR knockout) would increase leptin signaling in a developing fish (by increasing leptin sensitivity), and therefore accelerate bone deposition compared with the wild-type. For adult fish on HFD, endospanin knockout would rescue the leptin sensitivity [as it does in mice (Couturier et al., 2007)], and therefore, rescue the bone volume (Figure 1). Bone remodeling in adult mice requires leptin signaling, as $>90 \%$ of the mesenchymal stromal cells (MSCs) capable of forming bones express the leptin receptor (Zhou et al., 2014; Yue et al., 2016). Zebrafish MSCs that form bones also express LepR, which signals through Jak/Stat pathways (Giovannone et al., 2019). Although endospanin expression has not been documented in MSCs, it is documented to interact with RAB GTPases (Hirvonen et al., 2013) which are active in MSCs' exosomes that participate in bone fracture repair (Blanc and Vidal, 2018). Therefore, the components of both leptin signaling and leptin sensitivity are (potentially) both present in MSC.

We hypothesize that the normal development of bones in wild-type fish would result from high leptin sensitivity, via limiting endospanin expression. This may be achieved by generating endospanin ${ }^{-/+}$heterozygotes, or full knockouts via clustered regularly interspaced short palindromic repeatsCRISPR-associated protein 9 (CRISPR-CAS9) (Talbot and Amacher, 2014). Further, we hypothesize that normal bone turnover in adults would result from relatively low leptin sensitivity (higher endospanin expression). Increasing the expression of a gene product is typically more difficult than knockout approaches in zebrafish, although knock-ins have been achieved (Wierson et al., 2020). We predict that we can increase endospanin expression with diet, and adults on HFD would have very low leptin sensitivity (highest endospanin expression) and lowest bone volume, reflected in resorbed scales (Carnovali et al., 2018) and lower bone mineral density in the skeleton. In summary, we hypothesize that high leptin sensitivity promotes osteogenesis, and low leptin sensitivity promotes bone resorption (both mediated by endospanin). This hypothesis is informed by data reported for ob/ob mice, which have high leptin sensitivity, and respond to rescued leptin signaling with osteogenesis (Turner et al., 2013, 2015, 2017). If the hypothesis is supported, it would indicate that endospanin signaling is conserved, and not altered by the lack of endospanin/leptin receptor gene proximity in Teleosts. If 
not supported, it may be that endospanin and leptin signaling are decoupled in Teleosts. This could be pursued further by studying endospanin function in non-Teleost fish clades (gar, Family Lepisosteidae) that have the gene synteny shared with all other vertebrates (Londraville et al., 2017).

\section{CONCLUSION}

Here we develop the hypothesis that leptin sensitivity variation underlies the response of bone to leptin, and propose that leptin sensitivity is modulated by endospanin expression. We assert that studies in non-rodent models, such as zebrafish, will aid in unraveling the seemingly contradictory results in rodents (mostly conducted with leptin-signaling deficient mutants), because zebrafish have similar molecular toolsets to rodents, with the advantage of non-destructive sampling (using scales). We develop this hypothesis by outlining an experimental design in zebrafish to further develop the role of leptin signaling in bone dynamics. Finally, we understand that leptin sensitivity is best known for its role in obesity (Liu et al., 2018), and indeed, mice made extremely leptin sensitive via endospanin knockdown are resistant to obesity (Couturier et al., 2007). In fact, endospanin's regulation of leptin signaling (in an energy-balance context) has been the focus of most endospanin functional studies (Bailleul et al., 1997; Jeon et al., 2010; Séron et al., 2011; Lancel et al., 2018). Therefore, understanding endospanin's role in bone dynamics, especially given the uniqueness of gene loci for these genes in Teleost fish, will likely pay dividends toward understanding the role of leptin resistance in obesity in addition to its role in bone dynamics.

\section{REFERENCES}

Akhtar, W., de Jong, J., Pindyurin, A. V., Pagie, L., Meuleman, W., de Ridder, J., et al. (2013). Chromatin position effects assayed by thousands of reporters integrated in parallel. Cell 154, 914-927. doi: 10.1016/j.cell.2013.07. 018

Baek, K., and Bloomfield, S. A. (2009). $\beta$-Adrenergic blockade and leptin replacement effectively mitigate disuse bone loss. J. Bone Miner. Res. 24, 792799. doi: 10.1359/jbmr.081241

Bailleul, B., Akerblom, I., and Strosberg, A. D. (1997). The leptin receptor promoter controls expression of a second distinct protein. Nucleic Acids Res. 25, 27522758. doi: 10.1093/nar/25.14.2752

Beekman, K. M., Veldhuis-Vlug, A. G., den Heijer, M., Maas, M., Oleksik, A. M., Tanck, M. W., et al. (2019). The effect of raloxifene on bone marrow adipose tissue and bone turnover in postmenopausal women with osteoporosis. Bone 118, 62-68. doi: 10.1016/j.bone.2017.10.011

Blanc, L., and Vidal, M. (2018). New insights into the function of Rab GTPases in the context of exosomal secretion. Small GTPases 9, 95-106. doi: 10.1080/ 21541248.2016.1264352

Burguera, B., Hofbauer, L. C., Thomas, T., Gori, F., Evans, G. L., Khosla, S., et al. (2001). Leptin reduces ovariectomy-induced bone loss in rats. Endocrinology 142, 3546-3553. doi: 10.1210/endo.142.8.8346

Carnovali, M., Luzi, L., Terruzzi, I., Banfi, G., and Mariotti, M. (2018). Metabolic and bone effects of high-fat diet in adult zebrafish. Endocrine 61, 317-326. doi: 10.1007/s12020-017-1494-z

Chehab, F. F., Lim, M. E., and Lu, R. (1996). Correction of the sterility defect in homozygous obese female mice by treatment with the human recombinant leptin. Nat. Genet. 12, 318-320. doi: 10.1038/ng0396-318

\section{NOMENCLATURE}

Gene, mutant, and protein names are written in the convention for each species.

\section{DATA AVAILABILITY STATEMENT}

The original contributions presented in the study are included in the article/supplementary material, further inquiries can be directed to the corresponding author.

\section{AUTHOR CONTRIBUTIONS}

RL drafted the manuscript, which was reviewed and edited by MT, QL, and JA. All authors contributed to the ideas presented in this manuscript.

\section{FUNDING}

This work was supported by the NIH Grant 1 R15 DK124790$01 \mathrm{~A} 1$ to $\mathrm{RL}, \mathrm{QL}$, and JA [RL principle investigator (PI)].

\section{ACKNOWLEDGMENTS}

This work is a contribution from the Program in Integrated Bioscience, University of Akron, Akron, OH, United States.

Copeland, D. L., Duff, R. J., Liu, Q., Prokop, J., and Londraville, R. L. (2011). Leptin in teleost fishes: an argument for comparative study. Front. Physiol. 2:26. doi: 10.3389/fphys.2011.00026

Couturier, C., Sarkis, C., Séron, K., Belouzard, S., Chen, P., Lenain, A., et al. (2007). Silencing of OB-RGRP in mouse hypothalamic arcuate nucleus increases leptin receptor signaling and prevents diet-induced obesity. Proc. Natl. Acad. Sci. U.S.A. 104, 19476-19481. doi: 10.1073/pnas.0706671104

Ducy, P., Amling, M., Takeda, S., Priemel, M., Schilling, A. F., Beil, F. T., et al. (2000). Leptin inhibits bone formation through a hypothalamic relay: a central control of bone mass. Cell 100, 197-207. doi: 10.1016/s0092-8674(00)8 1558-5

Foldes, J., Shih, M. S., and Levy, J. (1992). Bone structure and calcium metabolism in obese Zucker rats. Int. J. Obes. Relat. Metab. Disord. 16, 95-102.

Giovannone, D., Paul, S., Schindler, S., Arata, C., Farmer, D. T., Patel, P., et al. (2019). Programmed conversion of hypertrophic chondrocytes into osteoblasts and marrow adipocytes within zebrafish bones. eLife 8:e42736. doi: 10.7554/ eLife. 42736

Guzmán, A., Hernández-Coronado, C. G., Rosales-Torres, A. M., and HernándezMedrano, J. H. (2019). Leptin regulates neuropeptides associated with food intake and GnRH secretion. Ann. Endocrinol. 80, 38-46. doi: 10.1016/j.ando. 2018.07.012

Hamrick, M. W. (2004). Leptin, bone mass, and the thrifty phenotype. J. Bone Min. Res. 19, 1607-1611. doi: 10.1359/JBMR.040712

Hamrick, M. W. (2007). Leptin and bone: a consensus emerging? Int. Bone Miner. Sci. Bonekey 4, 99-107. doi: 10.1138/20070254

He, J., Ding, Y., Nowik, N., Jager, C., Eeza, M. N. H., Alia, A., et al. (2021). Leptin deficiency affects glucose homeostasis and results in adiposity in zebrafish. J. Endocrinol. 249, 125-134. doi: 10.1530/JOE-20-0437 
Hirvonen, M. J., Büki, K. G., Sun, Y., Mulari, M. T. K., Härkönen, P. L., and Väänänen, K. H. (2013). Novel interaction of Rab13 and Rab8 with endospanins. FEBS Open Biol. 3, 83-88. doi: 10.1016/j.fob.2013.01.004

Jeon, J.-P., Shim, S.-M., Nam, H.-Y., Ryu, G.-M., Hong, E.-J., Kim, H.-L., et al. (2010). Copy number variation at leptin receptor gene locus associated with metabolic traits and the risk of type 2 diabetes mellitus. BMC Genomics 11:426. doi: 10.1186/1471-2164-11-426

Johnson, J. M., Maher, J. W., Samuel, I., Heitshusen, D., Doherty, C., and Downs, R. W. (2005). Effects of gastric bypass procedures on bone mineral density, calcium, parathyroid hormone, and vitamin D. J. Gastrointest. Surg. 9, 11061110; discussion1110-1111. doi: 10.1016/j.gassur.2005.07.012

Kamstra, K., Rizwan, M. Z., Horsfield, J. A., Pretz, D., Shepherd, P. R., Grattan, D. R., et al. (2021). Leptin regulates glucose homeostasis via the canonical WNT pathway. bioRxiv [Preprint] doi: 10.1101/2021.02.16.431518

Kaufman, B. A., Warren, M. P., Dominguez, J. E., Wang, J., Heymsfield, S. B., and Pierson, R. N. (2002). Bone density and amenorrhea in ballet dancers are related to a decreased resting metabolic rate and lower leptin levels. J. Clin. Endocrinol. Metab. 87, 2777-2783. doi: 10.1210/jcem.87.6.8565

Lancel, S., Hesselink, M. K. C., Woldt, E., Rouillé, Y., Dorchies, E., Delhaye, S., et al. (2018). Endospanin-2 enhances skeletal muscle energy metabolism and running endurance capacity. JCI Insight 3:e98081. doi: 10.1172/jci.insight.98081

Liu, J., Yang, X., Yu, S., and Zheng, R. (2018). The leptin resistance. Adv. Exp. Med. Biol. 1090, 145-163. doi: 10.1007/978-981-13-1286-1 8

Liu, Q., Dalman, M., Chen, Y., Akhter, M., Brahmandam, S., Patel, Y., et al. (2012). Knockdown of leptin A expression dramatically alters zebrafish development. Gen. Comp. Endocrinol. 178, 562-572. doi: 10.1016/j.ygcen.2012. 07.011

Lleras-Forero, L., Winkler, C., and Schulte-Merker, S. (2020). Zebrafish and medaka as models for biomedical research of bone diseases. Dev. Biol. 457, 191-205. doi: 10.1016/j.ydbio.2019.07.009

Londraville, R. L., Macotela, Y., Duff, R. J., Easterling, M. R., Liu, Q., and Crespi, E. J. (2014). Comparative endocrinology of leptin: assessing function in a phylogenetic context. Gen. Comp. Endocrinol. 203, 146-157. doi: 10.1016/j. ygcen.2014.02.002

Londraville, R. L., Prokop, J. W., Duff, R. J., Liu, Q., and Tuttle, M. (2017). On the molecular evolution of leptin, leptin receptor, and endospanin. Front. Endocrinol. 8:58. doi: 10.3389/fendo.2017.00058

Meng, X.-H., Tan, L.-J., Xiao, H.-M., Tang, B.-S., and Deng, H.-W. (2019). Examining the causal role of leptin in bone mineral density: a mendelian randomization study. Bone 125, 25-29. doi: 10.1016/j.bone.2019.05.006

Michel, M., Page-McCaw, P. S., Chen, W., and Cone, R. D. (2016). Leptin signaling regulates glucose homeostasis, but not adipostasis, in the zebrafish. Proc. Natl. Acad. Sci. U.S.A. 113, 3084-3089. doi: 10.1073/pnas.1513212113

Motyl, K. J., and McCabe, L. R. (2009). Leptin treatment prevents type I diabetic marrow adiposity but not bone loss in mice. J. Cell Physiol. 218, 376-384. doi: $10.1002 /$ jcp. 21608

Münzberg, H., Singh, P., Heymsfield, S. B., Yu, S., and Morrison, C. D. (2020). Recent advances in understanding the role of leptin in energy homeostasis. F1000Res 9, F1000FacultyRev-451. doi: 10.12688/f1000research.24260.1

Philbrick, K. A., Wong, C. P., Branscum, A. J., Turner, R. T., and Iwaniec, U. T. (2017). Leptin stimulates bone formation in ob/ob mice at doses having minimal impact on energy metabolism. J. Endocrinol. 232, 461-474. doi: 10 . 1530/JOE-16-0484

Reid, I. R., Baldock, P. A., and Cornish, J. (2018). Effects of leptin on the skeleton. Endocr. Rev. 39, 938-959. doi: 10.1210/er.2017-00226

Roujeau, C., Jockers, R., and Dam, J. (2019). Endospanin 1 determines the balance of leptin-regulated hypothalamic functions. Neuroendocrinology 108, 132-141. doi: 10.1159/000494557

Ruhl, C. E., and Everhart, J. E. (2002). Relationship of serum leptin concentration with bone mineral density in the United States population. J. Bone Miner. Res. 17, 1896-1903. doi: 10.1359/jbmr.2002.17.10.1896

Séron, K., Couturier, C., Belouzard, S., Bacart, J., Monté, D., Corset, L., et al. (2011). Endospanins regulate a postinternalization step of the leptin receptor endocytic pathway. J. Biol. Chem. 286, 17968-17981. doi: 10.1074/jbc.M111.224857
Seth, A., Stemple, D. L., and Barroso, I. (2013). The emerging use of zebrafish to model metabolic disease. Dis. Models Mech. 6, 1080-1088. doi: 10.1242/dmm. 011346

Takeshita, N., Mutoh, S., and Yamaguchi, I. (1995). Osteopenia in genetically diabetic $\mathrm{db} / \mathrm{db}$ mice and effects of $1 \alpha$-hydroxyvitamin D3 on the osteopenia. Life Sci. 56, 1095-1101. doi: 10.1016/0024-3205(95)00046-9

Talbot, J. C., and Amacher, S. L. (2014). A streamlined CRISPR pipeline to reliably generate zebrafish frameshifting alleles. Zebrafish 11, 583-585. doi: 10.1089/zeb. 2014.1047

Tonelli, F., Bek, J. W., Besio, R., De Clercq, A., Leoni, L., Salmon, P., et al. (2020). Zebrafish: a resourceful vertebrate model to investigate skeletal disorders. Front. Endocrinol. 11:489. doi: 10.3389/fendo.2020.00489

Tortoriello, D. V., McMinn, J. E., and Chua, S. C. (2007). Increased expression of hypothalamic leptin receptor and adiponectin accompany resistance to dietaryinduced obesity and infertility in female C57BL/6J mice. Int. J. Obes. 31, 395-402. doi: 10.1038/sj.ijo.0803392

Turner, R. T., Dube, M., Branscum, A. J., Wong, C. P., Olson, D. A., Zhong, X., et al. (2015). Hypothalamic leptin gene therapy reduces body weight without accelerating age-related bone loss. J. Endocrinol. 227, 129-141. doi: 10.1530/ JOE-15-0280

Turner, R. T., Kalra, S. P., Wong, C. P., Philbrick, K. A., Lindenmaier, L. B., Boghossian, S., et al. (2013). Peripheral leptin regulates bone formation. J. Bone Miner. Res. 28, 22-34. doi: 10.1002/jbmr.1734

Turner, R. T., Philbrick, K. A., Kuah, A. F., Branscum, A. J., and Iwaniec, U. T. (2017). Role of estrogen receptor signaling in skeletal response to leptin in female ob/ob mice. J. Endocrinol. 233, 357-367. doi: 10.1530/JOE-17-0103

Welt, C. K., Chan, J. L., Bullen, J., Murphy, R., Smith, P., DePaoli, A. M., et al. (2004). Recombinant human leptin in women with hypothalamic amenorrhea. N. Engl. J. Med. 351, 987-997. doi: 10.1056/NEJMoa040388

Wierson, W. A., Welker, J. M., Almeida, M. P., Mann, C. M., Webster, D. A., Torrie, M. E., et al. (2020). Efficient targeted integration directed by short homology in zebrafish and mammalian cells. Elife 9:e53968. doi: 10.7554/eLife.53968

Yang, D.-C., Tsay, H.-J., Lin, S.-Y., Chiou, S.-H., Li, M.-J., Chang, T.-J., et al. (2008). cAMP/PKA regulates osteogenesis, adipogenesis and ratio of RANKL/OPG mRNA expression in mesenchymal stem cells by suppressing leptin. PLoS One 3:e1540. doi: 10.1371/journal.pone.0001540

Yue, R., Zhou, B. O., Shimada, I. S., Zhao, Z., and Morrison, S. J. (2016). Leptin receptor promotes adipogenesis and reduces osteogenesis by regulating mesenchymal stromal cells in adult bone marrow. Cell Stem Cell 18, 782-796. doi: 10.1016/j.stem.2016.02.015

Zhang, Y., Proenca, R., Maffei, M., Barone, M., Leopold, L., and Friedman, J. M. (1994). Positional cloning of the mouse obese gene and its human homologue. Nature 372, 425-432. doi: 10.1038/372425a0

Zhou, B. O., Yue, R., Murphy, M. M., Peyer, J. G., and Morrison, S. J. (2014). Leptinreceptor-expressing mesenchymal stromal cells represent the main source of bone formed by adult bone marrow. Cell Stem Cell 15, 154-168. doi: 10.1016/j. stem.2014.06.008

Conflict of Interest: The authors declare that the research was conducted in the absence of any commercial or financial relationships that could be construed as a potential conflict of interest.

Publisher's Note: All claims expressed in this article are solely those of the authors and do not necessarily represent those of their affiliated organizations, or those of the publisher, the editors and the reviewers. Any product that may be evaluated in this article, or claim that may be made by its manufacturer, is not guaranteed or endorsed by the publisher.

Copyright (C) 2022 Londraville, Tuttle, Liu and Andronowski. This is an open-access article distributed under the terms of the Creative Commons Attribution License (CC BY). The use, distribution or reproduction in other forums is permitted, provided the original author(s) and the copyright owner(s) are credited and that the original publication in this journal is cited, in accordance with accepted academic practice. No use, distribution or reproduction is permitted which does not comply with these terms. 